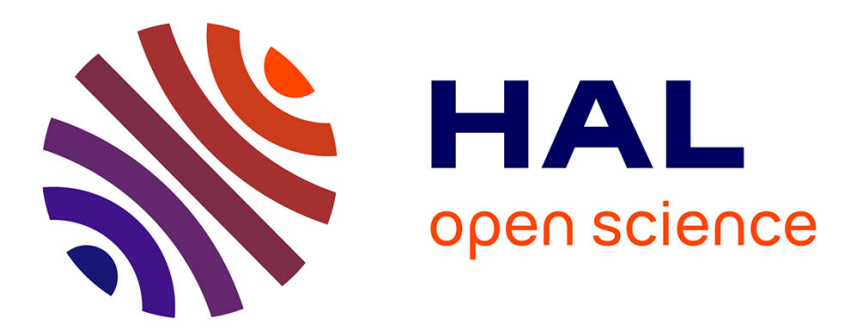

\title{
AMORPHOUS METALS STUDIED BY SUPERCONDUCTIVE TUNNELING
}

\author{
C. Granqvist
}

\section{To cite this version:}

C. Granqvist. AMORPHOUS METALS STUDIED BY SUPERCONDUCTIVE TUNNELING. Journal de Physique Colloques, 1975, 36 (C2), pp.C2-97-C2-101. 10.1051/jphyscol:1975220 . jpa00216268

\section{HAL Id: jpa-00216268 https://hal.science/jpa-00216268}

Submitted on 1 Jan 1975

HAL is a multi-disciplinary open access archive for the deposit and dissemination of scientific research documents, whether they are published or not. The documents may come from teaching and research institutions in France or abroad, or from public or private research centers.
L'archive ouverte pluridisciplinaire HAL, est destinée au dépôt et à la diffusion de documents scientifiques de niveau recherche, publiés ou non, émanant des établissements d'enseignement et de recherche français ou étrangers, des laboratoires publics ou privés. 


\title{
AMORPHOUS METALS STUDIED BY SUPERCONDUCTIVE TUNNELING (*)
}

\author{
C. G. GRANQVIST (**) \\ Physics Department, Chalmers University of Technology \\ Fack, S-402 20 Gothenburg 5, Sweden
}

\begin{abstract}
Résumé. - Nous avons pu utiliser la forme induite par les phonons dans les courbes d'effet tunnel supraconducteur pour examiner le degré d'ordre structural dans des films évaporés sur support refroidi. L'état amorphe est toujours caractérisé par une structure distincte à des énergies typiques des phonons longitudinaux. Dans des films d'alliages les températures de transformation d'un état à l'autre ont pu être identifiées avec celles où il se produit une discontinuité dans la variation de la résistivité avec la température. Ces températures sont reliées aux points de fusion des solutés purs. Les qualités vibrationnelles dans les films amorphes sont influencées par les dimensions à un moindre degré que dans les films microcristallins. Les températures de transformation sont augmentées dans des films très minces.

Abstract. - The phonon induced structure in tunneling curves has been used to investigate the degree of lattice order in vapour quenched films. The amorphous state is always characterized by one pronounced structure at energies typical for longitudinal phonons. In alloys the temperatures of transformation from one state of order to another could be identified with those where steps occurred in resistance $v s$. temperature plots. These temperatures scale with the melting points of the pure solutes. The vibration properties of amorphous films are much less influenced by sample dimensions than in microcrystalline films. The order transformations take place at increased temperatures in very thin layers.
\end{abstract}

1. Introduction. - When metal vapour is condensed onto a liquid-helium-cooled substrate the small diffusivity of the adsorbate leads to a highly disordered atomic arrangement. Such vapour quenched (V. Q.) films have been studied by diffraction of electrons or X-rays. From the compilation of data in Table $I$ it is seen that $\mathrm{Be}, \mathrm{Ga}$ and $\mathrm{Bi}$ form amorphous (A) structures by vapour quenching, whereas the other pure elements are crystalline with a short range order $\left(\mathrm{C}_{S R O}\right)$. The mean grain size is roughly $10 \mathrm{~nm}$ for thick films [4]. The alloys display amorphous structures which is reasonable as the impurities prevent crystallization. Only non-transition elements are included in Table I since the results on the transition metals differ very much between different works.

In this work we report on superconducting tunneling into V. Q. films. Provided the electron-phonon coupling is not too weak one obtains the function $\alpha^{2}(\omega) F(\omega)$ (where $\alpha^{2}$ is an averaged frequency dependent electronphonon coupling strength, and $F$ is the phonon distribution) mirrored in the experimental $\mathrm{d}^{2} I / \mathrm{d} V^{2} v s . V$ curves [12] ( $I$ is the tunnel current and $V$ is the bias across the barrier of the tunnel junction). As $\alpha^{2}(\omega)$ varies slowly in comparison with $F(\omega)$ one gets a good picture of the phonon spectrum by studying the second

(*) Supported by the Swedish Natural Science Research Council.

(**) Present address : Dept. of Appl. Phys. Cornell University, Ithaca, N. Y. 14853, USA. derivative of the tunnel current. This technique can be applied to the metals of Table I with the exceptions of $\mathrm{Be}$ and $\mathrm{Zn}$ that have very weak electron-phonon interactions $[13,14]$. After an outline of the experimental procedure in Section 2 we report on such phonon induced tunneling structure in various elements and

\section{TABLE I}

Compilation of results from diffraction measurements on vapour quenched metal films

\begin{tabular}{|c|c|c|c|}
\hline Metal & $\begin{array}{l}\text { Lattice } \\
\text { order }\left({ }^{(}\right)\end{array}$ & $\begin{array}{c}\text { Exp. } \\
\text { technique }\left({ }^{b}\right)\end{array}$ & Reference \\
\hline $\mathrm{Be}$ & $\mathrm{A}$ & $\mathrm{E}$ & {$[1-3]$} \\
\hline $\mathrm{Al}$ & $\mathrm{C}_{\mathrm{SRO}}$ & $\mathrm{E}$ & [4] \\
\hline $\mathrm{Zn}$ & $\mathrm{C}_{\mathrm{SRO}}$ & $\mathrm{E}$ & [4] \\
\hline $\mathrm{Ga}$ & $\mathrm{A}$ & $\mathrm{E}$ & {$[1,5-8]$} \\
\hline In & $\mathrm{C}_{\mathrm{SRO}}$ & $\bar{E}$ & [4] \\
\hline $\mathrm{Sn}$ & $\mathrm{C}_{\text {SRO }}$ & $E, X$ & {$[5,9]$} \\
\hline $\mathrm{Hg}$ & $\mathrm{C}_{\mathrm{SRO}}$ & E & [4] \\
\hline $\mathrm{Tl}$ & $\mathrm{C}_{\mathrm{SRO}}$ & $\mathrm{E}$ & [4] \\
\hline $\mathrm{Pb}$ & $\mathrm{C}_{\mathrm{SRO}}$ & $\mathrm{E}$ & {$[4,10]$} \\
\hline $\mathrm{Bi}$ & A & $\mathrm{E}$ & {$[1,5,6,10,11]$} \\
\hline $\mathrm{SnCu}$ & A & $E, X$ & {$[5,9]$} \\
\hline$\overline{\mathrm{Pb}}-\mathrm{Bi}$ & A & E & {$[1,2,10]$} \\
\hline
\end{tabular}

$\left({ }^{a}\right)$ A : amorphous; $\mathrm{C}_{\mathrm{SRO}}$ : crystalline, short range order.

(b) $\mathrm{E}$ : electron diffraction; $\mathrm{X}: \mathrm{X}$-ray diffraction. 
alloys in Section 3. We also investigate the influence on the function $\alpha^{2} F$ from very small film thicknesses. These experiments, that are based on measurements of the superconducting transition temperatures and energy gaps, are reported in Section 4. Annealing data for V. Q. alloys are described in Section 5 and in Section 6 the stabilization of the metastable phases are discussed.

2. Experimental technique. - The alloys are produced by sealing off the components in quartz tubes containing $\mathrm{He}$ gas and melting in an HF-furnace at such a high temperature that full solubility is achieved. After quenching from the liquid in water, grains of the alloys (normally produced by filing) are put in the feeding mechanism of a flash evaporation unit. Condensation of alloy vapour onto a predeposited and oxidized Al strip on a single crystal quartz substrate in our evaporator-cryostat [14] allows tunnel junctions of the conventional Al/oxide/metal type to be produced. The substrate is cooled by liquid ${ }^{3} \mathrm{He}$ and remains below $2 \mathrm{~K}$ at the surface during evaporation. The tunnel junctions can be cooled to $0.3 \mathrm{~K}$.

The $\mathrm{d}^{2} I / \mathrm{d} V^{2}$ vs. $V$ curves are obtained by harmonic detection of the off-balance signal in a bridge coupling [15]. The superimposed ac signal is generally $200 \mu \mathrm{V}$ RMS.

Film thicknesses are read on a quartz crystal oscillator microbalance with a relative resolution of about $0.1 \mathrm{~nm}$ and an absolute accuracy of some 10-20\%.

3. Phonon induced tunneling structure of amorphous films. - The lower curve of figure 1 shows a

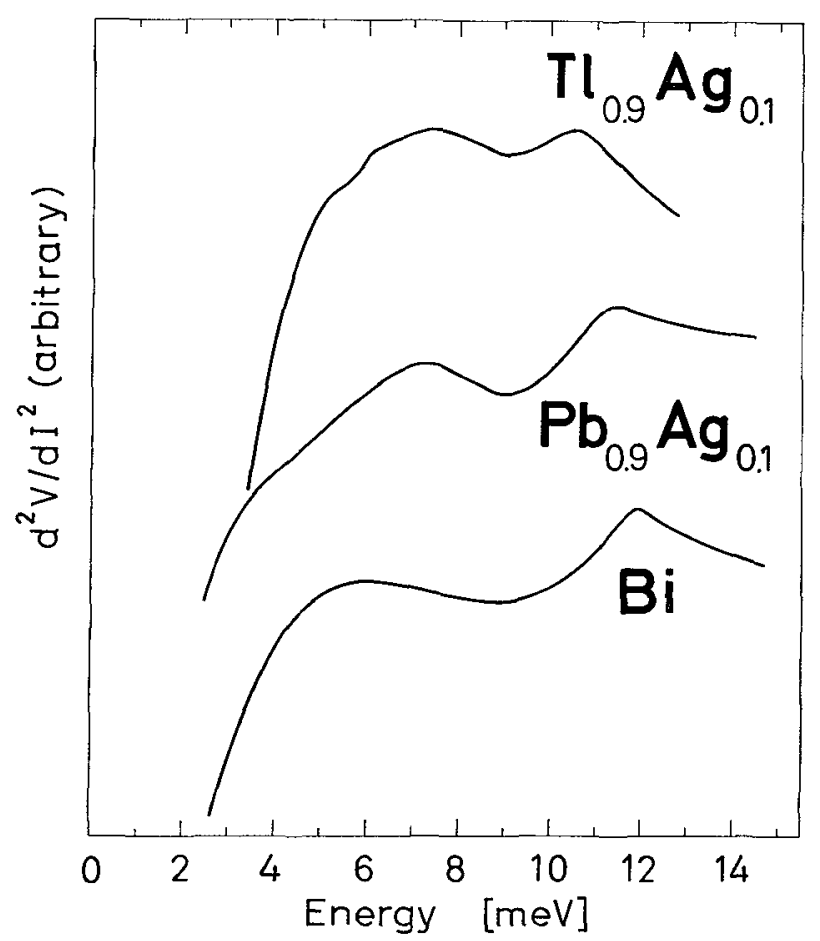

FIG. 1. - $\mathrm{d}^{2} V / \mathrm{d} I^{2}$ vs. $V$ plots for amorphous $\mathrm{Tl}_{0.9} \mathrm{Ag}_{0.1}$, $\mathrm{Pb}_{0 .} . \mathrm{Ag}_{0.1}$ and $\mathrm{Bi}$ $\mathrm{d}^{2} V / \mathrm{d} I^{2}$ vs. $V\left(^{1}\right)$ plot for $\mathrm{V} . \mathrm{Q}$. Bi in its amorphous state (cf. Table I). The curve is characterized by a shallow dip centered around $\sim 9 \mathrm{meV}$ in excellent agreement with the results of [16].

The data for $\mathrm{Pb}_{0.9} \mathrm{Ag}_{0.1}$ in figure 1 is qualitatively similar to the one for amorphous $\mathrm{Bi}$, and the dip is located at the same energy. The curve is an example from our investigation of $\mathrm{Pb}_{0.9} \mathrm{M}_{0.1}$ alloys $(\mathrm{M}: \mathrm{Na}$, $\mathrm{Mg}, \mathrm{Zn}, \mathrm{Ga}, \mathrm{Ge}, \mathrm{Ag}, \mathrm{Cd}, \mathrm{In}, \mathrm{Sn}, \mathrm{Sb}, \mathrm{Te}$ ) [17] where identical curves were registered for the V. Q. alloys with one exception : $\mathrm{Pb}_{0.9} \mathrm{In}_{0.1}$ displayed structure at low energy reminiscent of the transversal modes of pure $\mathrm{Pb}$. This alloy is the only one with full solid solubility.

The plot for $\mathrm{Tl}_{0.9} \mathrm{Ag}_{0.1}$ also has the characteristic dip around $9 \mathrm{meV}$ as its only reproducible phonon induced feature. Due to the lower electron phonon interaction in this alloy the structure is much weaker than for $\mathrm{Pb}$ or $\mathrm{Bi}$. In our investigation of $\mathrm{Tl}_{0.9} \mathrm{X}_{0.1}$ alloys (X : Na, Zn, Ag, Cd, Sn) [18] we observed some contributions from transversal modes except in $\mathrm{Tl}_{0.9} \mathrm{Ag}_{0.1}$; this is the only alloy with vanishing solid solubility.

If we define an amorphous state as one lacking clearly resolved transversal phonon structure in $\mathrm{d}^{2} I / \mathrm{d} V^{2}$ vs. $V$ curves (in agreement with the well known similarity between the V.Q. amorphous and the liquid states) we conclude that quenching onto a liquidhelium-cooled substrate gives amorphous alloys provided solid solubility is absent.

Several studies of phonon effects in amorphous films by superconductive tunneling are found in the literature ; these are compiled in Table II. The most salient feature of the $\mathrm{d}^{2} I / \mathrm{d} V^{2}$ vs. $V$ curves is always one pronounced minimum located at an energy $\varepsilon_{\min }$. In many of

\section{TABLE II}

Phonon induced structures by superconductive tunneling into amorphous metals

\begin{tabular}{|c|c|c|}
\hline Metal & $\varepsilon_{\min }[\mathrm{meV}]$ & Reference \\
\hline \multirow[t]{2}{*}{$\mathrm{Ga}$} & 18 & [16] \\
\hline & $\sim 17$ & {$[20]$} \\
\hline \multirow[t]{4}{*}{$\mathrm{Bi}$} & 8.5 & [16] \\
\hline & 8.5 & [21] \\
\hline & $8.5-9.0$ & [22] \\
\hline & $8.5-9.0$ & This work \\
\hline $\mathrm{Sn}_{0.9} \mathrm{Cu}_{0.1}$ & $\sim 13$ & {$[22,23]$} \\
\hline $\mathrm{Tl}_{0.9} \mathrm{Ag}_{0.1}$ & 9.2 & This work \\
\hline $\mathrm{Pb}_{0.9} \mathrm{M}_{0.1}\left({ }^{a}\right)$ & $8.5-9.0$ & {$[17]$} \\
\hline $\mathrm{Pb}_{0.9} \mathrm{Cu}_{0.1}$ & 8.5 & [22] \\
\hline \multirow[t]{2}{*}{$\mathrm{Pb}-\mathrm{Bi}$} & $8.0-9.0$ & [21] \\
\hline & $8.0-9.0$ & {$[20]$} \\
\hline${ }_{.9} \mathrm{Cu}_{0.1}$ & 8.5 & [22] \\
\hline
\end{tabular}

$\left(^{a}\right) \mathrm{M}: \mathrm{Na}, \mathrm{Mg}, \mathrm{Zn}, \mathrm{Ga}, \mathrm{Ge}, \mathrm{Ag}, \mathrm{Cd}, \mathrm{Sn}, \mathrm{Sb}, \mathrm{Te}$.

(1) Except very close to zero bias this is very similar to $\mathrm{d}^{2} I / \mathrm{d} V^{2} v s . V$. 
the works the function $\alpha^{2}(\omega) F(\omega)$ has been extracted by computation [12]. These spectra consist of two peaks where the high energy one corresponds to $\varepsilon_{\min }$, and the smeared low energy peak is obtained by subtraction off an assumed variation according to the BCS theory of superconductivity [19]; the shape of this peak is uncertain, as it is not clearly visible in the $\mathrm{d}^{2} I / \mathrm{d} V^{2} v s . V$ plots. It is found from figure 2 that $\varepsilon_{\min } \propto M^{-1 / 2}$ for the investigated materials. This implies that the average value of the (isotropic) force constants do not differ significantly among the various amorphous metals.

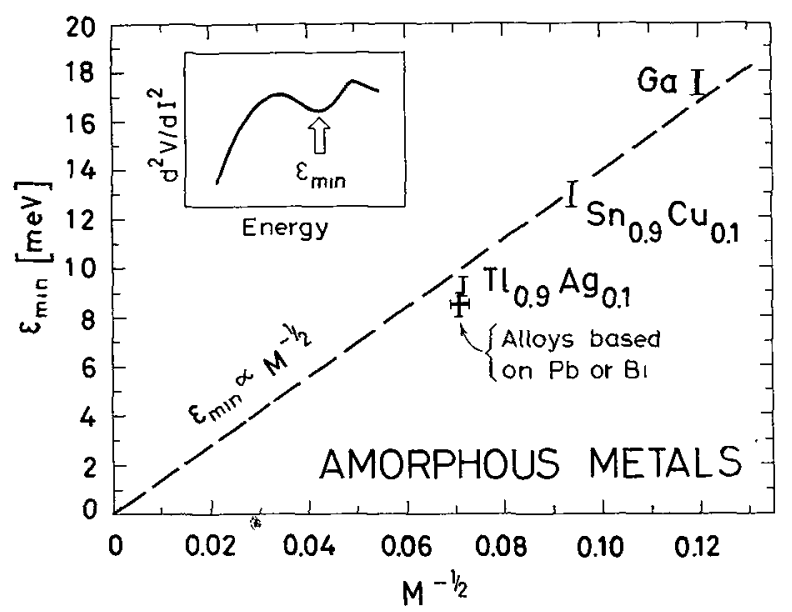

Fig. 2. $-\varepsilon_{\min }$ (defined in the insert) versus $M^{-1 / 2}$ for the amorphous metals of Table II. The vertical bars represent the experimental spread; the horizontal bar indicates the mass spread among the alloys based on $\mathrm{Pb}$ and $\mathrm{Bi}$.

Several of the metals that form $\mathrm{C}_{\mathrm{SRO}}$ states (cf. Table I) by vapour quenching have also been tested by superconductive tunneling. For In [16], Sn [16], Tl [18] and $\mathrm{Pb}[16,17,22]$ the $\mathrm{d}^{2} I / \mathrm{d} V^{2} v s . V$ plots display clearly resolved transversal modes.

4. Size dependent changes of the vibration properties. - By going to very small film thicknesses $(t)$ one expects the influence from the surface modes to be increasingly dominant. In a microcrystalline film one intuitively expects these modes to become significant when $t$ is of the same order as the mean crystallite size. An amorphous film, being in a state of maximum disorder, is presumed to be much less affected by sample size. Superconducting tunneling has been used to verify this hypothesis.

A straightforward measurement of $\mathrm{d}^{2} I / \mathrm{d}^{2}$ vs. $V$ curves as a function of $t$ is rather awkward as (i) the surface mode contribution is located at low energies where the peaked electron density of states provides a rapidly sloping background for the interesting effects ; and (ii) in an ultrathin film low energy structure, that is not reflecting $\alpha^{2}(\omega) F(\omega)$, always occurs [24]. A better method is to study the ratio $2 \Delta(0) / k_{\mathrm{B}} T_{\mathrm{c}}$ versus $t$ $\left(\Delta(0)\right.$ is the zero temperature energy gap, $k_{\mathrm{B}}$ is Bolzmann's constant and $T_{\mathrm{c}}$ is the superconducting transition temperature). In a superconductor with appreciable electron phonon coupling the phonon mediated, attractive electron-electron interaction is damped such that both $\Delta(0)$ and $T_{c}$ are depressed relatively their weak-coupling (BCS) values. $T_{c}$, which is obtained in the presence of the thermal phonons, will be most affected and thus increased ratios of $2 \Delta(0) / k_{\mathrm{B}} T_{\mathrm{c}}$ result. The deviation from the weakcoupling result of 3.53 is consequently a measure of the low energy part of the function $\alpha^{2}(\omega) F(\omega)$.

Figure 3 reports on such measurements for V. Q. microcrystalline $\mathrm{Pb}$ and amorphous $\mathrm{Ga}$ and $\mathrm{Bi}$ [25]. It is immediately clear that the increased disorder obtained by going to small size gives a significant contribution to $\alpha^{2}(\omega) F(\omega)$ for $\mathrm{Pb}$, whereas the effect on $\mathrm{Ga}$ and $\mathrm{Bi}$ is much smaller.

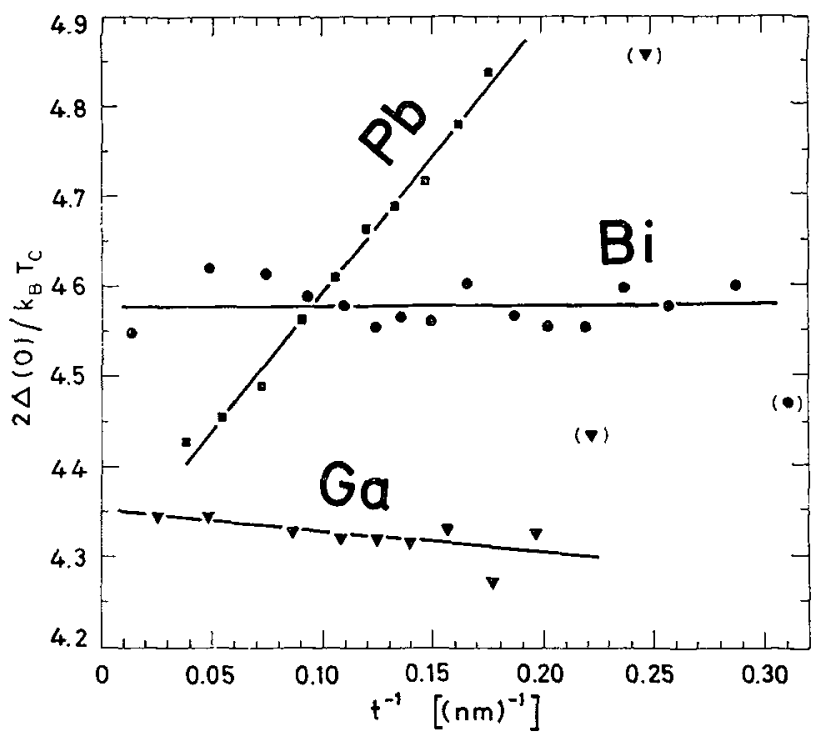

Fig. 3. $-2 \Delta(0) / k_{\mathrm{B}} T_{\mathrm{c}}$ versus $t^{-1}$ for $\mathrm{Pb}, \mathrm{Ga}$ and $\mathrm{Bi}$. The films are investigated at several intermediate $t$ 's during the build-up. Bracketed points are uncertain as in the extreme thin limit neither the $\mathcal{U}(0)$ 's nor the $T_{\mathrm{e}}$ 's are sharply defined. The straight lines represent least squares fits.

5. Annealing of the vapour quenched films. - The lattice order of a V. Q. film increases by annealing (annealing temp., $T_{\mathrm{A}}$ ). This gives a change of the phonon induced structures in the $\mathrm{d}^{2} I / \mathrm{d} V^{2}$ vs. $V$ curves, and also a decrease of the resistivity measured along the film. Figure 4 examplifies these data by showing annealing results for $\mathrm{Pb}_{0.9} \mathrm{Ga}_{0.1}$.

In the $\mathrm{V}, \mathrm{Q}$. state a high-resistivity phase with a $\mathrm{d}^{2} I / \mathrm{d} V^{2}$ vs. $V$ curve showing amorphicity (cf. Fig. 1) is obtained. Annealing makes the resistivity drop irreversibly, particularly in the range $20 \mathrm{~K}<T_{\mathrm{A}}<30 \mathrm{~K}$. If the anneal is interrupted and the film is recooled to the lowest temperature, new $\mathrm{d}^{2} I / \mathrm{d} V^{2}$ vs. $V$ data (cf. $T_{\mathrm{A}}=30 \mathrm{~K}$ in Fig. 4) indicate a $\mathrm{C}_{\mathrm{SRO}}$ state. Note the well developed transversal mode dip centered around $4 \mathrm{meV}$. Heating again to $T_{\mathrm{A}}$ 's higher than $30 \mathrm{~K}$, makes the resistivity continue along the curve of figure 4 (as long as the temperature is lower than the maximal $T_{A}$, the resistivity changes reversibly). The procedure is 


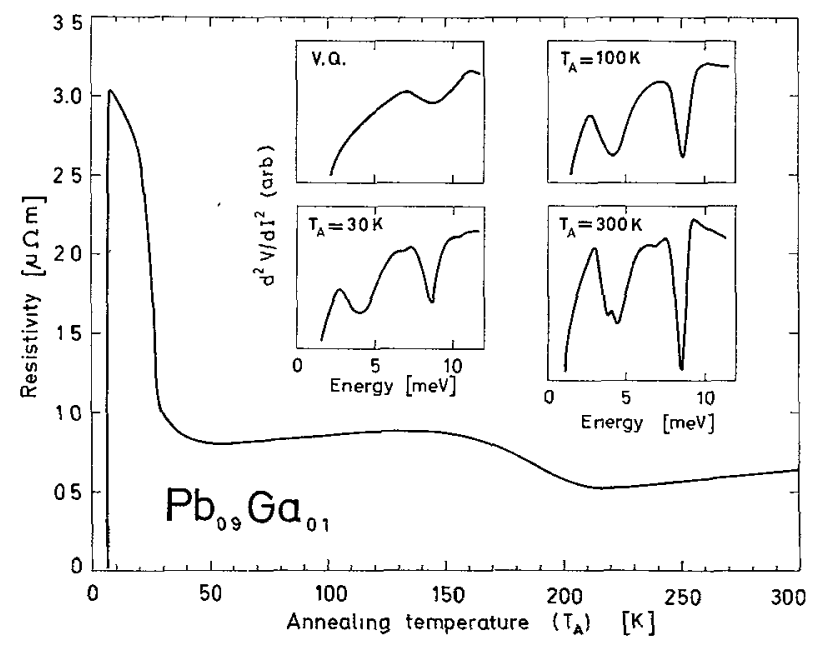

FrG. 4. - The main figure shows resistivity versus annealing temperature for $\mathrm{Pb}_{0.9} \mathrm{Ga}_{0.1}$. The phonon induced tunneling structures for the film as deposited and after anneals to $30 \mathrm{~K}$, $100 \mathrm{~K}$ and $300 \mathrm{~K}$ are shown in the inserts.

repeated by halting the annealing at $T_{\mathrm{A}}=100 \mathrm{~K}$ and at $T_{\mathrm{A}}=300 \mathrm{~K}$. The $\mathrm{d}^{2} I / \mathrm{d}^{2}$ vs. $V$ plots show that the $\mathrm{C}_{\mathrm{SRO}}$ state remains at $100 \mathrm{~K}$ but at room temperature the phonon induced structure characteristic for pure lead is obtained. The lattice order state is now crystalline, long range ordered $\left(\mathrm{C}_{\mathrm{LRO}}\right)$.

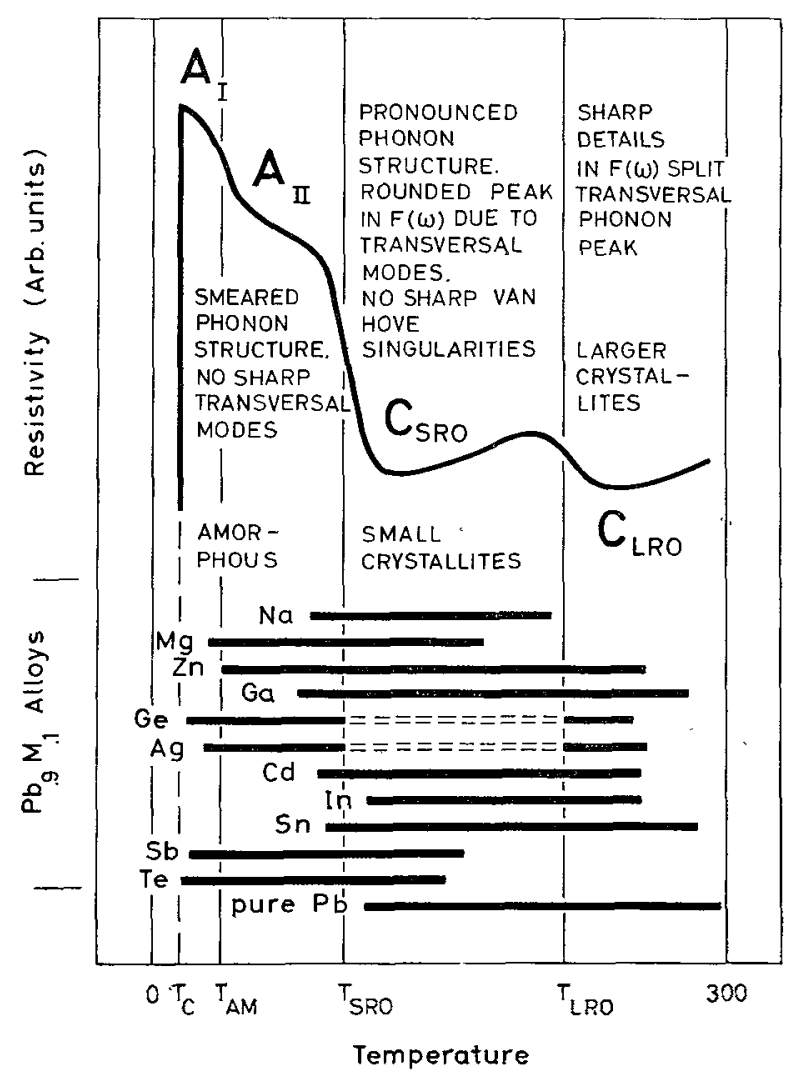

FIG. 5. - The upper part shows a master curve for the annealing of the $\mathrm{Pb}$-based alloys. The particular range of this curve applicable to each alloy is denoted by the thick lines in the lower part. The endpoints are qualitative only.
Looking at the resistivity change it is tempting to ascribe the sharp step at low temperatures to an order transformation $\mathrm{A} \rightarrow \mathrm{C}_{\mathrm{SRO}}$, and the weaker step around $180 \mathrm{~K}$ to a transformation $\mathrm{C}_{\mathrm{SRO}} \rightarrow \mathrm{C}_{\mathrm{LRO}}$, where the latter one must be accompanied by a precipitation of the impurities when solid solubility is nil.

By observing the order transformation temperature from the resistivity curves and determining the particular change of the lattice order from the $\mathrm{d}^{2} I / \mathrm{d} V^{2}$ vs. $V$ data, it is possible to draw one master curve for the annealing behaviour of all the alloys based on $\mathrm{Pb}$ or $\mathrm{TI}$ discussed in Section 3 (cf. [17] and [18]). This is shown in figure 5 for the $\mathrm{Pb}_{0.9} \mathrm{M}_{0.1}$ alloys. The range of this curve covered by each alloy is indicated in the lower part of the figure. For three alloys $-\mathrm{Pb}_{0.9} \mathrm{Ge}_{0.1}$, $\mathrm{Pb}_{0.9} \mathrm{Ag}_{0.1}$ and $\mathrm{Tl}_{0.9} \mathrm{Ag}_{0.1}$ - the intermediate $\mathrm{C}_{\mathrm{SRO}}$ state is not observed, but the alloys transform directly $A \rightarrow C_{\text {LRo }}$ upon heating.

In some alloys two different amorphous states $\left(A_{1}\right.$ and $\mathrm{A}_{\mathrm{II}}$; cf. Fig. 5) must be postulated as a small resistivity step is observed at very low temperatures while the amorphous state remains (as judged from the tunnel data).

6. Stability of the metastable phases. - It is indicated in figure 5 that the amorphous states are stable to very different temperatures in the various $\mathrm{Pb}$-based alloys. The crystallization temperature $\left(T_{\text {cryst }}\right)$ where the films transform from an amorphous state to either $\mathrm{C}_{\mathrm{SRO}}$ or $\mathrm{C}_{\mathrm{LRO}}$ is plotted in figure 6 . The melting point of the pure impurity element $\left(T_{\text {melt }}^{\mathrm{M}}\right)$ is also shown and it is seen that they vary in very much the same manner. This is not the case if one plots atomic diameters or Debye temperatures correspondingly [26]. The same conclusions can be drawn for the transformations $A_{I} \rightarrow A_{I I}$ and $C_{\text {SRO }} \rightarrow C_{\text {LRO }}$. The behaviour is similar for the Tl-based alloys, although fewer data are available. Thus the melting temperature of the impurity element governs the stability of the metastable phases.

Other properties, like the impurity diffusion activation energy, are proportional to $T_{\text {melt }}$ [27]. Hence the data indicate that ordering occurs when the impurities can diffuse.

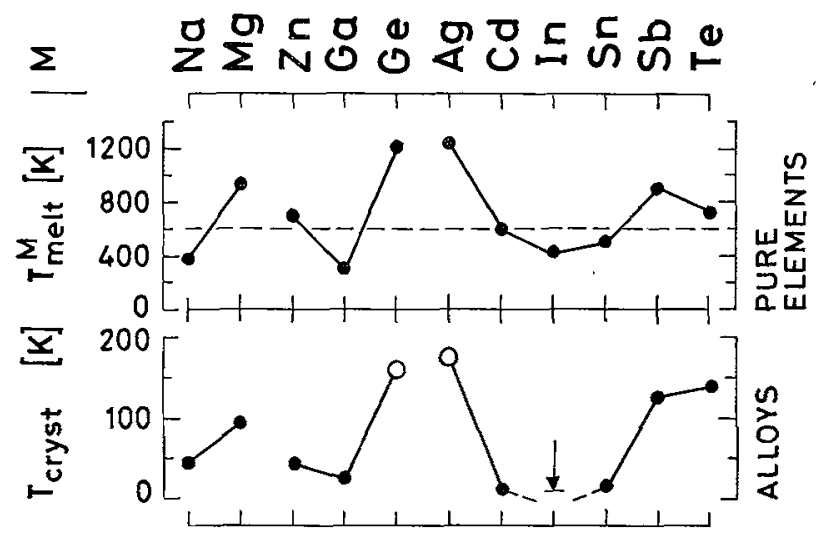

Fig. 6. - The temperature for crystallization ( $\left.T_{\text {cryst }}\right)$ is shown for several $\mathrm{Pb}_{0.9} \mathrm{M}_{0.1}$ alloys, and the correlation to the melting point of the impurity element $\left(T_{\mathrm{melt}}^{\mathrm{M}}\right)$ is evident. 
From figure 6 it is evident that the alloys that crystallize directly into the $\mathrm{C}_{\text {LRo }}$ state also have the highest $T_{\text {melt }}^{\mathrm{M}}$. The results for the alloys based on $\mathrm{Tl}$ and $\mathrm{Pb}$ can be summarized by

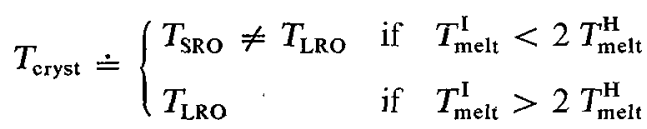

where $T_{\text {SRO }}$ and $T_{\text {LRO }}$ are defined in figure 6 , and $\mathrm{I}(\mathrm{H})$ denotes impurity (host) element. Evidently the evolved heat during the crystallization, that amounts to roughly half of that of melting for V. Q. $\mathrm{Sn}_{0.9} \mathrm{Cu}_{0.1}$ [28], suffices to prevent an intermediate short range ordered state from being stabilized.

The transformation temperatures are influenced by the film thicknesses and enhanced values are observed in the extremely thin limit. Figure 7 shows an annealing curve for $\mathrm{Pb}_{0.9} \mathrm{Cd}_{0.1}$ with $t=6.1 \mathrm{~nm}$, which is very close to the thickness demanded to form an electrically continuous layer. $T_{\text {cryst }}$ takes place around $50 \mathrm{~K}$ which can be compared with the much lower value for a film of about twice that thickness, as reported in figure 6 . The thickness dependence can be explained by thermodynamic arguments [11]. Above $T_{\mathrm{A}}=230 \mathrm{~K}$ the resistance rises steeply and eventually the film becomes disconnected. This must be caused by an agglomeration into large islands.

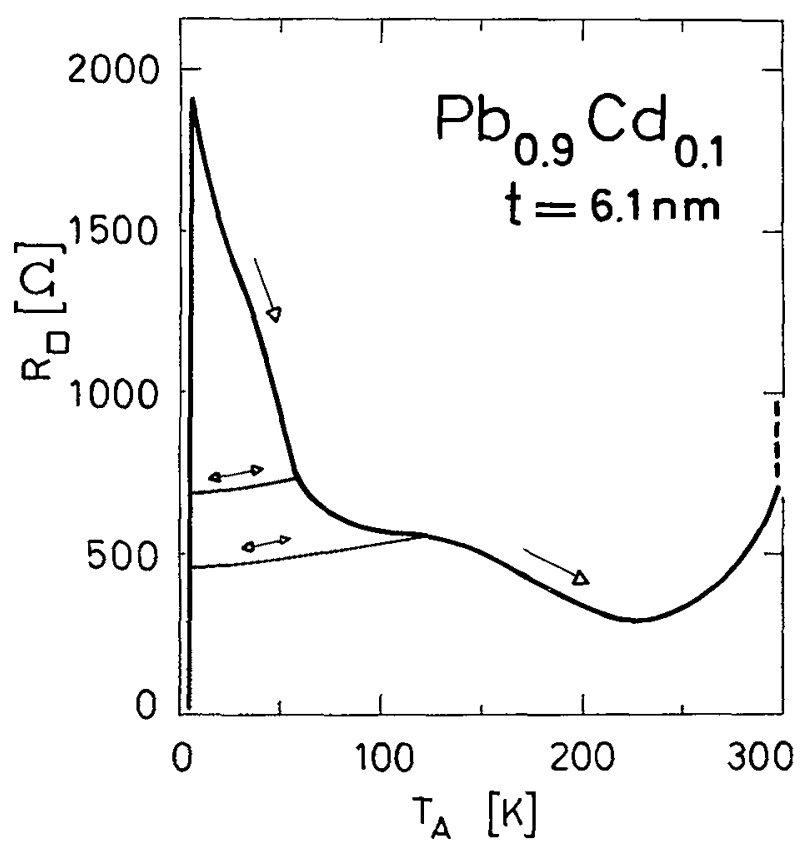

Fig. 7. - Resistance per square (i. e. resistivity times $t^{-1}$ ) versus annealing temperature $\left(T_{\mathrm{A}}\right)$ for a very thin $\mathrm{Pb}_{0.9} \mathrm{Cd}_{0.1}$ films. Double-headed arrows denote a reversible $R_{\square} v s . T_{A}$ relation.

References

[1] FuJIME, S., Japan J. Appl. Phys. 5 (1966) 59.

[2] FuJime, S., Japan J. Appl. Phys. 5 (1966) 778.

[3] Curzon, A. E. and Mascall, A. J., J. Phys. C(Solid State Phys.) 2 (1969) 382.

[4] Bülow, H. and Buckel, W., Z. Phys. 145 (1956) 141.

[5] BuCkel, W., Z. Phys. 138 (1954) 136.

[6] FuIme, S., Japan J. Appl. Phys. 5 (1966) 764.

[7] Ishikawa, T., Phys. Stat. Sol. (a) 19 (1973) 347.

[8] Komnk, Yu. F., Belevtsev, B. Y. and Yatsuk, L. A., Thin Solid Films 21 (1974) 189.

[9] RüHL, W., Z. Phys. 138 (1954) 121.

[10] Baier, P., Z. Phys. 213 (1968) 89.

[11] Komnik, Yu. F., Beleytsey, B. I. and Yatsuk, L. A., $Z$ h. Eksp. Teor. Fiz. 63 (1972) 2226 [English transl. Soviet Phys. JETP 36 (1973) 1177].

[12] MCMillan, W. L. and Rowell, J. M., in Superconductivity, ed. Parks R. D. (Marcel Dekker, New York) 1969 Ch. 11 , p. 561 .

[13] Granovist, C. G. and Claeson, T., $Z$. Phys., in press.

[14] Granqvist, C. G. and Claeson, T., J. Low Temp. Phys. 10 (1973) 735.

[15] Adler, J. G. and Jackson, J. E., Rev. Sci. Instrum. 37 (1966) 1049.
[16] Zavaritskil, N. V., Zh. Eksp. Teor. Fiz, 57 (1969) 752 [English transl. Soviet Phys. JETP 30 (1970) 412].

[17] Grangvist, C. G. and Claeson, T., J. Low Temp. Phys. 13 (1973) 1.

[18] Grangist, C. G. and Claeson, T., Z. Phys., to be published.

[19] Bardeen, J., Cooper, L. N. and Schrieffer, J. R., Phys. Rev. 108 (1957) 1175.

[20] JACkson, J. E., Briscoe, C. V. and Wühl, H., Physica (Utrecht) 55 (1971) 447.

[21] Leshie, J. D., Chen, J. T. and Chen, T. T., Can. J. Phys. 48 (1970) 2783.

[22] KNorr, K. and Barth, N., J. Low Temp. Phys. 4 (1971) 469.

[23] KNorr, K. and BARTH, N., Solid State Commun. 6 (1968) 791

[24] Granqvist, C. G. and Claeson, T., Phys. Rev. Lett. 31 (1973) 456 ; Phys. Kond. Mater., 18 (1974) 99

[25] Granquist, C. G. and Claeson, T., Phys. Lett. 45A (1973) 431.

[26] Granevist, C. G. and Claeson, T., Thin Solid Films 16 (1973) 65.

[27] Grimvall, G. and Suödin, S., Physica Scripta, in press.

[28] MöNCH, W., Z. Phys. 164 (1961) 229. 